\title{
Metacognição e leitura
}

\author{
Janete Aparecida da Silva Marini
}

A metacognição é um construto recente na literatura psicológica. Em geral, tem sido definida como o conhecimento ou atividade cognitiva que toma como seu objeto a cognição ou que regula qualquer aspecto da iniciativa cognitiva. Ela é chamada de metacognição porque seu sentido essencial é a “cognição acerca da cognição", ou seja, "pensar sobre o pensamento" (Flavell, Miller \& Miller, 1999).

Esse construto desempenha papel importante em muitos tipos de atividades cognitivas, incluindo a comunicação oral de informações, a compreensão oral, a compreensão em leitura, a escrita e a aquisição $\mathrm{da}$ linguagem, dentre outras. $\mathrm{Na}$ teoria do desenvolvimento cognitivo encontra-se o estabelecimento da relação entre a metacognição e o modo como os leitores planejam sua leitura, monitoram se estão compreendendo e regulam essa compreensão, revendo caminhos e estratégias, quando percebem que não estão entendendo o sentido e o conteúdo do texto (Jacobs \& Paris, 1987). Assim, pode-se entender a metacognição como o conhecimento e controle que a pessoa tem sobre sua própria cognição e atividades de aprendizagem. Isso implica em ter conhecimento do seu estilo de pensamento (processos e eventos cognitivos), o conteúdo dos mesmos (estruturas) e habilidade para controlar esses processos, com o objetivo de organizá-los, revisá-los e modificá-los em função dos resultados obtidos na aprendizagem (Bolívar, 2002).

O conhecimento sobre a cognição e a regulação da cognição são os dois componentes da metacognição. $O$ conhecimento sobre a cognição se refere ao que indivíduo sabe sobre a sua própria cognição, inclui o conhecimento sobre o eu e as habilidades do eu, o conhecimento sobre as variáveis da tarefa e estratégias para monitorar a execução. $O$ segundo componente, a regulação da cognição se refere a ações que ajudam os estudantes a controlar sua aprendizagem e apresentam como diferencial o fato de que podem ser desenvolvidas e aprimoradas via instrução (Bolívar, 2002; Boruchovitch, 1999; Carrel, Gadjusek \& Wise, 1998; Jacobs \& Paris, 1987; Scallon, 2000; Simpson \& Nist,2000; Brown e Palinscar, 1984).

Grande ênfase vem sendo dada ao uso da metacognição na leitura por diversos fatores. Dentre eles, destaca-se o fato que a metacognição enfatiza a participação ativa do leitor na análise da tarefa e o uso de estratégias metacognitivas de leitura. Verifica-se por meio dos estudos que os leitores pouco hábeis raramente usam estratégias metacognitivas de leitura para auxiliar à compreensão. Isso se deve ao fato de não conhecê-las ou não saber como usá-las quando encontram dificuldades na compreensão daquilo que estão lendo. Já os leitores habilidosos usam com freqüência uma variedade de estratégias de acordo com a complexidade do texto a ser lido. Por outro lado, os leitores iniciantes freqüentemente fazem confusão sobre que direção seguir ou o que fazer quando encontram dificuldades no texto (Duke \& Pearson, 2002; Joly \& Paula, 2005; Kopke, 1997)

Outro fato está relacionado à possibilidade de usar as estratégias como uma alternativa à instrução tradicional na leitura de textos escolares. Professores que não observam progressos no nível de compreensão em leitura de seus alunos têm usado a metacognição para ensinar estratégias a serem usadas antes, durante e depois da leitura (Jacobs \& Paris, 1987). A principal função das estratégias metacognitivas é oferecer ao leitor informações sobre sua ação e o progresso nela (Flavell, Miller \& Miller, 1999).

No treino para o desenvolvimento das estratégias metacognitivas, os professores devem dar instruções explicitas que especifiquem a direção que o aluno deve seguir, como por exemplo "Prestem atenção no caminho que o autor usa para comparar e contrastar a forma como os vários governos explicam o que é democracia" ou "Vejam como o autor muda a descrição toda vez que precisa caracterizar um personagem novo 
que está sendo introduzido na narrativa". Um dos objetivos do treino em estratégias de leitura é levar os alunos a atuarem na zona de desenvolvimento proximal-ZDP (Vygotsky, 1978). Para que os alunos atuem na ZDP e treinem a consciência metacognitiva, os textos utilizados para o treino devem ser adequados ao nível de instrução e/ou série em que está sendo realizado. Não pode ser tão fácil a ponto de não exigir o uso das estratégias metacognitivas e nem tão difícil a ponto de fazer o estudante se desmotivar e desistir da tarefa.

Num texto expositivo, a habilidade em identificar, representar e saber usar a estrutura textual é uma grande habilidade, pois quando o estudante consegue identificá-la pode organizar e reorganizar as informações e idéias nele contidas (Rhoder, 2002). Para atingir esse objetivo o professor pode trabalhar com a classe dividida em pequenos grupos de estudos, utilizando um texto que pode ser de geografia, português ou história dentre outros. O importante, no início, é usar um texto com assunto conhecido, pois o objetivo não é introduzir novos conhecimentos e sim treinar a consciência metacognitiva dos estudantes. Vale destacar que os estudantes devem aprender e praticar somente uma ou duas estratégias novas ao mesmo tempo.

Durante o treino de estratégias os alunos precisam perceber que estão avançando para aumentar e sustentar sua motivação. Para que isso ocorra, o professor deve informá-los e mostrar que o uso de estratégias pode ser útil quando estão tentando aprender algo novo. Nas atividades com esse fim, o docente explica qual o foco da ação e o quê os alunos aprenderão a identificar e a usar na leitura do texto, ensinando-os a usar as estratégias metacognitivas de leitura como uma ferramenta que auxilia na aprendizagem.

O professor pode também ensinar aos alunos a elaborarem perguntas e questões que guiarão seu pensamento, além de questões que os ajudarão a compreender melhor o que estão lendo. Como exemplo, pode ensinar a fazer o resumo de um editorial que foi lido coletivamente e então mandá-los praticar resumindo um texto que tenha a mesma estrutura em seu livro didático. Esse procedimento dá aos estudantes a oportunidade de usar o conhecimento acessível para praticar uma estratégia aprendida, permitindo-lhes desenvolver a estratégia de resumir o que foi lido e desenvolver a habilidade de identificar, representar e usar a estrutura de um texto, fato que é muito importante na competência leitora.

Já o domínio do conteúdo do texto pode ser explorado com o professor ensinando estratégias espaciais tais como organizar roteiros, mapas conceituais, relacionar informações de fontes diferentes com $\circ$ conhecimento prévio, transformando o conteúdo em representações concretas de conceitos complexos.

Uma queixa muito comum entre professores de alunos de $5^{\mathrm{a}}$ a $8^{\mathrm{a}}$ série é a de que os alunos não conseguem ler os textos narrativos com o nível de compreensão esperado nessas séries. Para que haja um progresso na compreensão em leitura é necessário que os alunos sejam preparados para ler, sendo importante ensiná-los a identificar onde estão os fatos principais de um texto. Os professores podem começar ensinando os alunos a lerem o sumário, verificando de que maneira ele reflete as idéias do autor, bem como, a relação de um assunto com o outro. É importante também, como já citado, enfatizar que identificar e usar a estrutura do texto poderá levá-los a ler com maior velocidade, compreender melhor e recordar as informações do texto.

Num segundo momento, o docente deve explicar aos alunos que há perguntas que ajudam a guiar o pensamento. É recomendável que o docente comece instruindo-os a pensar em perguntas que podem ser feitas ao texto para facilitar a compreensão. Deve-se permitir que trabalhem em grupos, que façam perguntas uns aos outros, indicando que podem fazer perguntas de causa e efeito, relacionadas ao tempo, ao modo de agir e a caracterização das personagens (se houver), comparando fatos e seqüência de eventos, dentre outras. O professor deve criar várias oportunidades para que os alunos possam praticar as estratégias em textos que vão ficando gradativamente mais complexos e ir introduzindo novas estratégias.

Finalizando, vale destacar que é muito importante que os professores incentivem e propiciem momentos em que os alunos precisem discutir suas idéias com 
seus pares e defender suas decisões. É necessário que haja a compreensão de que é importante para o aluno passar por esse processo, que $\circ$ faz pensar sobre o texto de uma maneira muito mais profunda e mais ativa, vendo outras perspectivas de interpretações do mesmo texto. É relevante também que o aluno tenha oportunidade de escutar e discutir processos cognitivos seus e de seus colegas de forma coletiva ou em grupos, fazendo uso assim da metacognição.

\section{Referências}

Bolívar, C. R. (2002). Mediación de estrategias metacognitivas en tareas divergentes y transferencia recíproca. Investigación y Postgrado, 17. Disponível em <http:// www.scielo.org/investigationypostgrado > .

Boruchovitch, E. (1999). Estratégias de aprendizagem e desempenho escolar: considerações para a prática profissional. Reflexão e Crítica, 12, 36I-376.

Brown, R., \& Palinscar, A. (1984). Reciprocal teaching of comprehension monitoring activies. Cognition and Instruction, I, I I7-I75.

Carrell, P. L., Gajdusek, L., \& Wise, T. (1998). Metacognition and EFL/ESL reading. Instructional Science, 26, 97-I I 2.

Duke, N. K., \& Pearson, P. D. (2002). Effective practices for developing reading comprehension. Em: A. E. Farstrup \& S.J. Samuels (Orgs.). What research has to say about reading instruction (pp.205-243). Newark: IRA.
Flavell, J. H. (1979). Metacognition and cognitive monitoring: a new area of cognitive-developmental inquiry. American Psychologist, 34, 906-91I.

Flavell, J. H , Miller, H. P. \& Miller, S. A. (1999). Desenvolvimento cognitivo (Trad. Claudia Dornelles). Porto Alegre. Artmed.

Jacobs, J. E., \& Paris, S. G. (1987). Children's metacognition about reading: Issues in definition, measurement, and instruction. Educational Psychologist, 22(3\&4), 255-278.

Joly, M. C. R. A., \& Paula, L. M. (2005). Avaliação do uso de estratégias de aprendizagem e a compreensão em leitura de universitários. Em: M. C. R. A., Joly, A. A. A., Santos \& F. F. Sisto (orgs). Questões do cotidiano universitário. (pp 3358). São Paulo. Casa do Psicólogo.

Kopcke F. H. (1997). Estratégias para desenvolver a metacognição e a compreensão de textos teóricos na universidade. Psicologia Escolar e Educacional, I (2 \& 3), 59-67.

Rhoder, C. (2002). Mindfull reading: Strategy training that facilitates transfer. Journal of Adolescent \& Adult Literacy, 45(6), 498-5I 2.

Scallon, G. (2000). Avaliação formativa e psicologia cognitiva: correntes e tendências. Em: J. Grégoire e cols., Avaliando as aprendizagens: os aportes da psicologia cognitiva. (B. Magne, trad.) (pp. I55-168). Porto Alegre. Artmed.

Simpson, M. L., \& Nist, S. L. (2000). An update on strategic learning: It's more than textbook reading strategies. Journal of Adolescent \& Adult Literacy, 43 (6), 528-54I.

Sobre a autora

Janete Aparecida da Silva Marini (janmarini@terra.com.br) é mestre em Avaliação Psicoeducaional pela Universidade São Francisco - Itatiba - SP 